\title{
'Science is My True Villain': Exploring STEM Classroom Dynamics Through Student Drawings
}

\author{
Mahati Kopparla ${ }^{1 *}$, Akash Kumar Saini ${ }^{2}$
}

\author{
1 University of Calgary, CANADA \\ 2 UNESCO MGIEP, INDIA
}

\section{*Corresponding Author: mahatikopparla1991@gmail.com}

Citation: Kopparla, M. and Saini, A. K. (2022). 'Science is My True Villain': Exploring STEM Classroom Dynamics Through Student Drawings. European Journal of STEM Education, 7(1), 03. https://doi.org/10.20897/ejsteme/11785

Published: February 18, 2022

\begin{abstract}
Classroom dynamics including interactions among peers and with teachers is a key component of students' STEM experiences, strongly influencing students' motivation to engage in the learning activities. Classroom dynamics and dialogue have been predominantly studied through longitudinal ethnographic observations of the classroom while the perspective of the students who are undergoing these experiences is largely unaccounted for. This research article showcases an empirical study that used student drawings to explore STEM classroom dynamics. In contrast with interviews, drawing allows the participant to illuminate their tacit knowledge and communicate ideas without interference from the researcher. The participants $(n=32)$, 9th grade students from 16 public schools in Northern India, were asked to create a poster with drawings and words to show their experiences and feelings in mathematics and science classrooms. A thematic analysis of students' work was performed to draw inferences about the classroom dynamics. The posters provided an opportunity for students to authentically express themselves and represent the social and emotional consequences of teacher behaviour in STEM classrooms. Concurring with previous classroom dynamics research, findings identified a strong need to reassess teaching practices in rural Indian context.
\end{abstract}

Keywords: STEM, classroom dynamics, dialogue, student drawings, developing country perspective

\section{INTRODUCTION}

In a world moving rapidly towards digitization and automation, there is an increasing demand for a STEM (Science, Technology, Engineering and Mathematics) literate workforce (World Economic Forum, 2020). STEM literacy is becoming synonymous with high performance on international assessments such as TIMSS and PISA, even though the scores are not representative of quality STEM education (Ozer, 2020; Sjøberg, 2015). The over emphasis on performance rather than learning is consequentially reflected in everyday teaching practices and classroom dynamics leading to negative attitudes towards STEM subjects (Barroso et al., 2021; Kaya and Yildirim, 2014).

STEM classroom dynamics has been predominantly studied through longitudinal ethnographic observations of the classroom (Jocuns, 2013; Kayi-Aydar and Miller, 2018). While this approach provides an external view of student interactions, the perspective of the students who are undergoing these experiences is largely unaccounted for. In order to improve student experiences in STEM classrooms, there is a need to understand their perception of the classroom and sources of anxiety. Towards addressing this gap, an empirical study was conducted to explore the role of student drawings in understanding STEM classroom dynamics. 


\section{LITERATURE REVIEW}

STEM classrooms, like any social space shared by diverse individuals, tend to have certain norms, socially constructed identities, and power structures (Tsukada and Perreault, 2016). Classroom dynamics is a broad term that encompasses all of these components in the classroom beyond academic content. It includes components such as (i) norms and expectations in the classroom, (ii) perceptions and behaviours of peers and teachers, and (iii) the physical configuration of the classroom (Omatsu, 2011). The complex interplay between the classroom elements creates unique dynamics within the classroom and shapes the educational experience of the students. Classroom dynamics have the potential to impact student behavioural, socioemotional, and academic outcomes (Wang et al., 2020).

Teacher expectation and behaviour is a critical element of classroom dynamics (Howe and Abedin, 2013). Teachers are known to form expectations for students based on indicators such as prior academic performance, socioeconomic status, and gender (Nathan et al., 2010). These flawed expectations from teachers translated into differential treatment of students (Flores, 2007). A 5-step path outlined by Wang et al. (2018) summarizes the effects teacher expectations and behaviour on student outcomes:

1. teacher forms expectation for students,

2. teacher behaves differently based on expectations,

3. student perceives teacher expectation,

4. student socio-psychological factors are influenced, and

5. student achievement outcomes are influenced.

Irrespective of actual teacher behaviour, students' perception of teacher differential treatment critically impacted student outcomes (Brey and Pauker, 2019). Often referred to as a 'the Pygmalion effect' or a 'self-fulfilling prophecy', teacher expectations can significantly predict student self-efficacy, attitudes and achievement outcomes in STEM subjects (Gentrup et al., 2020; Rosenthal and Jacobson, 1968).

Teachers not only influence student outcomes through direct interactions, but also moderate peer dynamics within the classroom. Through their behaviour in class, teachers model ways for students to interact and evaluate each other (Hendrickx et al., 2016). Consequently, teacher behaviour and differential treatment influences peers' perception of the student (Brey and Pauker, 2019; Montague and Rinaldi, 2001). Teacher expectations and academic achievement influence the formation of peer groups with high-achieving students selecting each other as friends (Véronneau et al., 2010). Peer perceptions and interactions are highly influential on student experiences, especially in middle school, as students strive to socially fit in. As social integration and academic outcomes are closely related, some students experiencing rejection or discrimination in the classroom may have difficulty in academic achievement (Schneider et al., 2012). In turn, poor academic performance reinforces biased treatment from peers and teachers.

Students develop their self-efficacy beliefs and identities as STEM learners based on the academic performance and perceptions of their peers and teachers (Hendrickx et al., 2016). While high expectations from teachers can improve student performance, low expectations create a significant challenge for them (Rosenthal and Jacobson, 1968; Zhan and Sherraden, 2011). In addition, teacher expectations and peer behaviour have an impact on student attitudes towards the subject and intent to pursue STEM careers (Benner and Mistry, 2007; Heaverlo, 2011; Lee et al., 2015). For example, teachers have a lower expectation for female students in subjects like mathematics, which contributes to an underrepresentation of women in related fields (Banerjee et al., 2018; Watson et al., 2015). However, female students were more likely to choose and stay in STEM majors when their female peers or friends had similar intentions (Raabe et al., 2019). Thus, classroom dynamics have the potential to shape students' selfperception and STEM career choices.

Impacted by their early STEM experiences, many students decide that STEM fields are too challenging or boring before they reach high school (PCAST, 2010). Poor attitudes towards STEM are also observed in students from rural schools in India (Menon et al., 2021). This trend consistently results in a shortage of qualified professionals in developed and developing countries (UNESCO, 2021). Given that student perception of classroom dynamics impacts student self-efficacy, attitudes, and achievement, there is a strong need to account for student voice and perception in classroom dynamics research. By integrating diverse perspectives and contexts, we could collectively work towards creating a conducive environment for developing positive STEM attitudes among students.

Drawings have been considered to provide a valuable insight into children's views, feelings and opinions (Puglionesi, 2016). In educational settings, drawings are noted as effective tools for learning (Prain and Tytler, 2012), assessment (Koester, 2015), and research (Bracher, 2003). In this study, drawing is positioned as a 'nonverbal language' that elicits images and reflections from lived experiences (Alerby and Bergmark, 2012). In contrast with interviews, drawing allows the participant to communicate their ideas without interference from the researcher (Mannay, 2010). Further, drawings have the potential to illuminate the tacit knowledge that might be common to 
the researcher and the participants (Alerby and Brown, 2008). Thus, student drawings were used as a tool to explore students' experiences within STEM classrooms.

\section{METHODS AND ANALYSIS}

The current study was a part of a larger project conducted in collaboration with a network of rural residential schools across India. The aim of the project was to support and improve mathematics and science teaching within the school system. The first step in the project was to assess the existing teaching practices and learning experiences within the science and mathematics classrooms. Towards this end, two-day workshops were conducted in several regions across India to engage with the science and mathematics teachers and underperforming students. Observations from one such student workshop session conducted in Northern India is presented here.

Participants $(\mathrm{n}=32)$ were 9th grade (ages 14-16) students from 16 rural residential schools in Northern India. Specifically, two students from each school who were identified as academically underperforming by their mathematics and science teachers were invited to participate. To ensure confidentiality, all students were seated in a classroom where only researchers were present and instructed not to write their names on the artwork. Students were asked to create a stand-alone poster with drawings and words to show their experiences and feelings in mathematics and science classrooms. Due to some design limitations of the workshop, group discussions about their classroom experiences were conducted in lieu of individual follow-up interviews with students.

Following the workshops with students and teachers, the project team conducted class observations in each of the participating schools. During this time, the team gained a deeper understanding of the school system, classroom dynamics, and student experiences through engagement with the whole class, teachers, and other administrative personnel. Thus, during the process of analysing the student posters, researchers were also informed by these experiences. Specifically, to analyse the student posters, and identify recurring patterns and themes, a critical visual methodology framework was used (Rose, 2001). Based on the questions identified by Rose (2001) and Guillemin (2004), the following questions about the poster were employed to guide the analysis:

a. What is being shown? What are the components of the poster? How are they arranged?

b. What do the different components signify?

c. What relationships are established between the components of the poster?

d. What knowledge and experiences are being deployed?

e. Who or what components are excluded from this representation?

f. Is this a contradictory image? (To other data or observation)

The students were bilingual, thus using English and Hindi in their art works. The analysis was conducted by researchers who were also fluent in Hindi and English. A translation for Hindi is provided wherever relevant.

\section{RESULTS}

Out of the 32 students, 3 of the student posters were excluded from the analysis as they depicted experiences from Civics and English classrooms. All of the remaining posters indicated a dislike for experiences associated with either mathematics or science or both classrooms. Through the posters, students provided explanations and examples of their classroom and subject experiences. About $79 \%$ of them indicated an academic difficulty as a part of the reason for their dislike. About $41 \%$ of the posters included an affective representation of their relationship with the subject. About $31 \%$ illustrated a classroom scene indicative of their experiences.

\section{Academic Difficulties}

A majority of the posters provided descriptions of particular topics and concepts that students found difficult. Students explained that they enjoyed topics in which they understood the content and could confidently answer test questions. On the other hand, they associated topics that were hard to understand with boredom and hatred. Students described their difficulty in science and maths by repeatedly referring to their 'marks' on the test and the test taking experiences. A few students explained that they tried very hard to study and learn the maths and science concepts, but somehow forgot or 'messed up' (गड़बड़) answers on the test leading to low scores. The low scores and inability to understand the topics triggered feelings of anxiety (परेशान) and confusion (दिमाग खराब literally translates to brain-damage) because of which they didn't feel like studying the subject anymore. They highlighted an expectation to remember diagrams, formulae, equations, descriptive answers, and mathematical solutions to be able to have a positive experience in maths and science classrooms. This expectation was a source of anxiety and fear for a majority of the participants (Figure 1). 


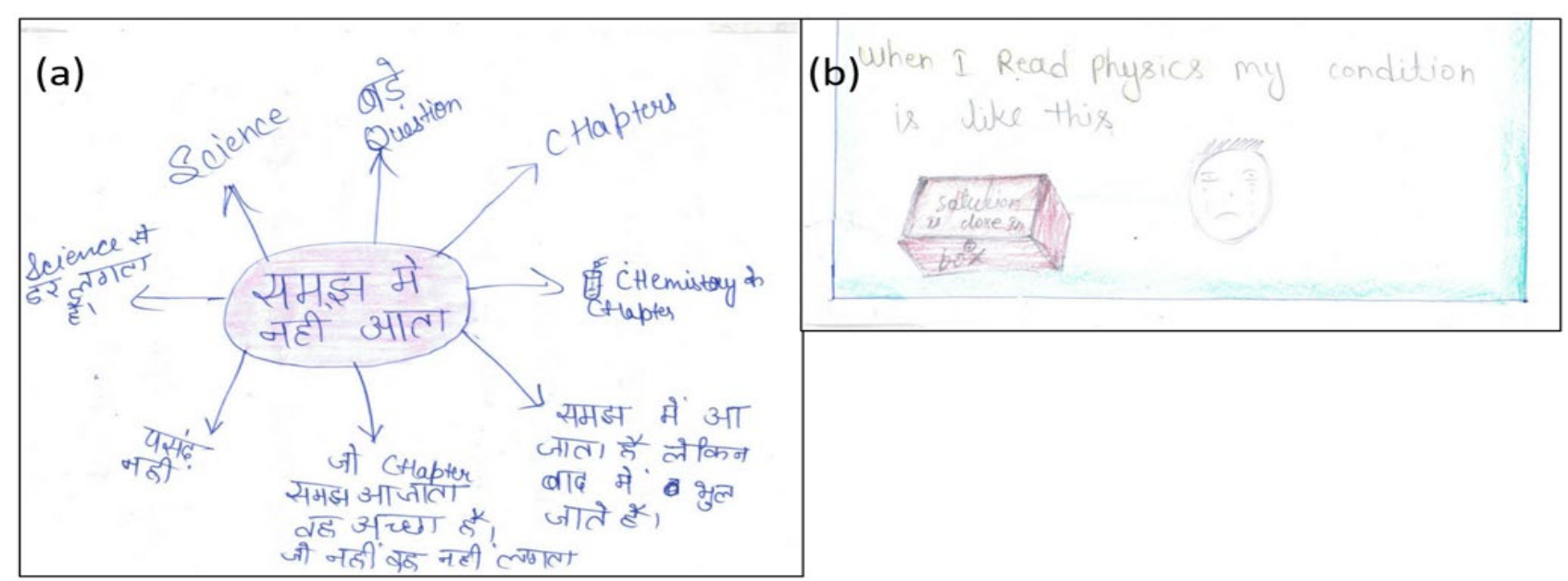

Figure 1. Student explanations of academic difficulty. (a) A central circle has the words "Cannot understand" with arrows leading to Science, long answer questions, chapters, chemistry chapter, 'could understand, but forget later', 'the chapters that I can understand, I feel good about them, but do not feel good about the other chapters', 'don't like', 'scared of Science' (listed clockwise starting from top left). (b) An illustration of 'when I read Physics, my condition is like this' showing a student in tears next to locked box where the 'solution is close[d] in'.

\section{Affective Representations}

Being in a residential setting, students spent almost all of their time with teachers and peers, leaving no separation between academic and social life. Thus the ability to perform well academically was a significant aspect of their life. Themes of dislike for maths and science were common among all student posters, but 12 of the students created an extremely emotional depiction of their feelings towards the subjects. In these posters, students depicted themselves as victims with unpleasant expressions. Two students personified mathematics as a ghost that's haunting them (see Figure 2), while three others cautioned that maths and science denote 'danger'.

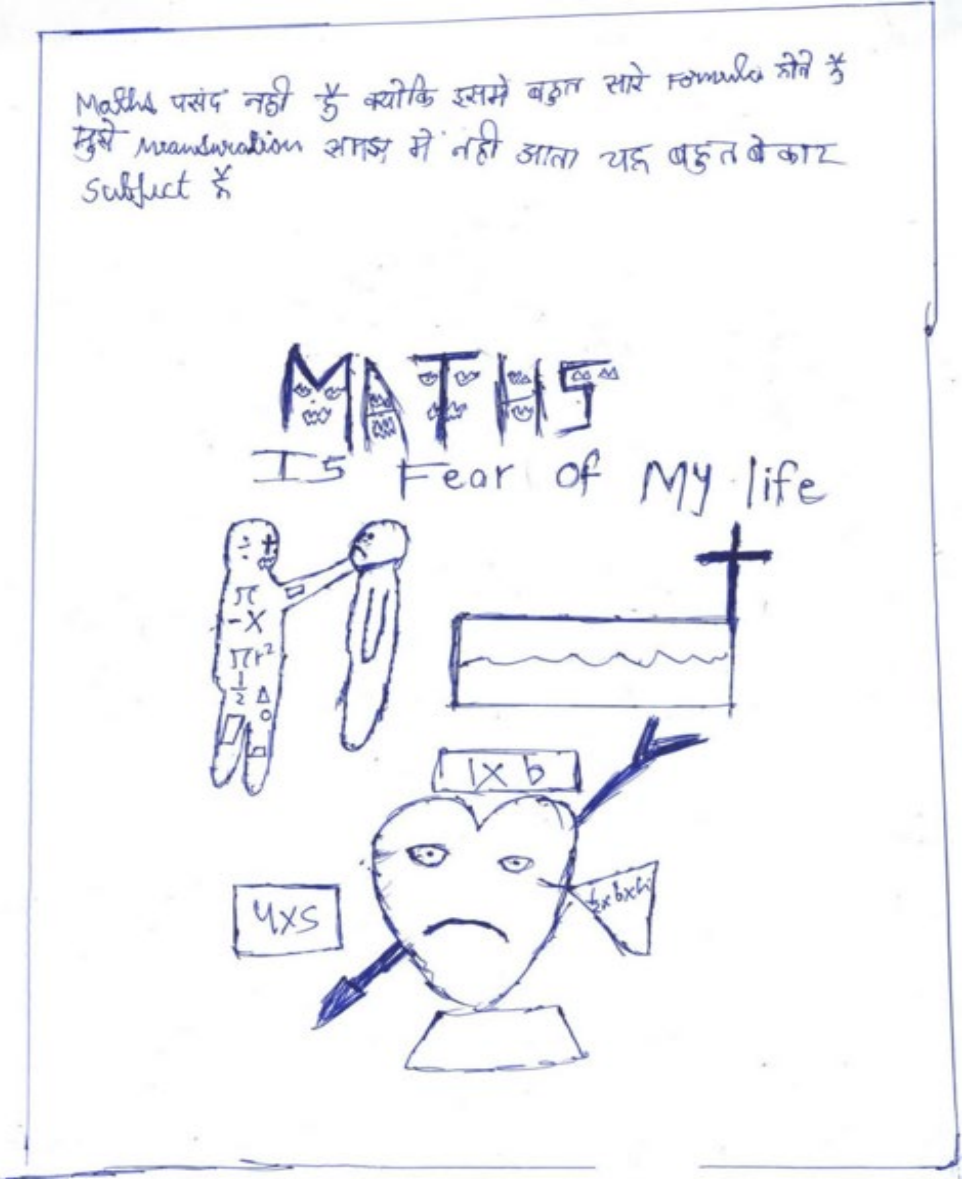

Figure 2. Example of personification of the subject 
Students explains that they do not want to study mathematics because there are too many formulae. They cannot understand the chapter 'mensuration' and feel mathematics is a waste subject. The illustration is titled 'Maths is the fear of my life' with maths having several angry faces as seen from Figure 2. A human form of mathematics symbols is holding the student by their neck and threatening to end their life. Next to them is a grave and a sad heart remembering mathematical formulae for area measurements from the chapter 'mensuration'. Several students represented an unpleasant physical sensation associated with science and maths such as their heart on fire, brain explosion, and head spinning. Students used the phrases 'science is my true villain' and 'maths is the fear of my life' to represent the antagonistic role of the STEM subjects in their life.

Sometimes, their teachers and textbooks appear disproportionately large (for example, Figure 3(d) and Figure 6), potentially indicative of the looming power over them. Two students particularly created disturbing artworks indicating that mathematics 'will be with them until the end of life' (हमारे जीवन के आखरी लम्हो तक जुड़ा है). Due to the intense emotions associated with science and maths, few students created representations of 'getting back at' science and maths. They wanted to show their anger and frustration by throwing their textbooks into the 'dustbin' or fire (see Figure 3). One student was particularly waiting for 'their time to scare mathematics away'.

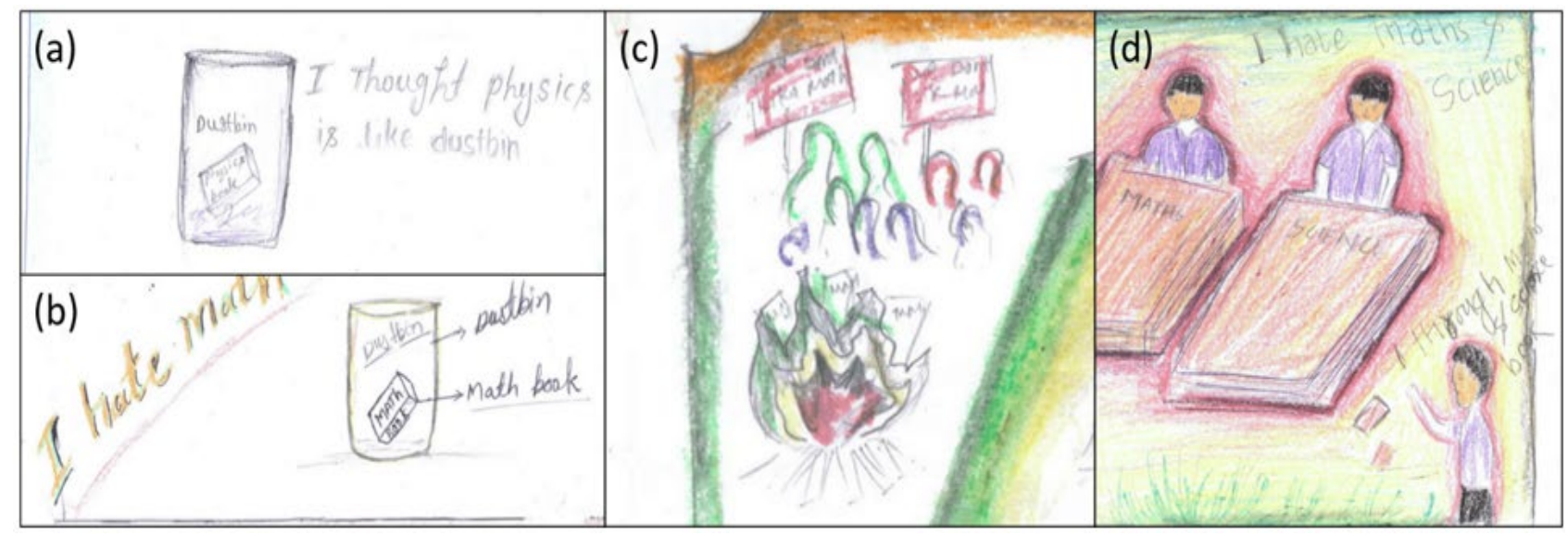

Figure 3. Examples of 'getting back at' maths and science. (a) A dustbin with a physics book inside it. Student describes 'I thought physics is like dustbin'. (b) Titled 'I hate math' a drawing of a math book in the dustbin. (c) A group of students holding placards 'I don't like math' are standing in front of a fire and throwing their mathematics textbooks into the fire. (d) Student sitting in front of extremely large mathematics and science textbooks saying 'I hate maths and science'. Another illustration of the same student on the corner throwing away books.

\section{Classroom Scene}

Eight students created drawings of a particular representative incident from their mathematics or science classroom. Most of the pictures represented a typical regimented classroom with the students seated in rows and columns facing the teacher and a black board. In all of the drawings, there was a one-way conversation from teacher to student with occasional response from the students. Based on the drawings, the dialogue with the teacher could be classified into two types, namely, (a) teacher explaining a concept and (b) teacher asking a question.

\section{Explaining a concept}

Four students created images of the teacher explaining a concept in class. The drawings showed students as bored, confused or unable to understand the topic. However, they were hesitant to voice their concerns and depicted themselves going through different emotions. Two of these drawings only represented themselves and the teacher while ignoring the existence of other students in the classroom (see Figure 4 and Figure 5).

Informed by our classroom observations, these depictions may represent the lack of collaborative learning opportunities and isolated learning experiences for the students. The classroom was completely teacher centred with a lack of communication between the teacher and student. As students were unable to follow the teachers who remained unaware of students' issues, students developed negative attitudes towards the topics. While the student in Figure 4 associated algebra with confusion, the student in Figure 5 associated physics class and textbook with danger.

Two students depicted some of their peers having a similar experience while the teachers were explaining a concept (see Figure 6 and Figure 7). Particularly, Figure 6 depicted a classroom where a small number of students who were able to understand the teacher were usually more vocal. This left the majority of the students at a disadvantage. However, both Figure 6 and Figure 7 represented students who took comfort in the sentiment that they were not alone in their struggles. 


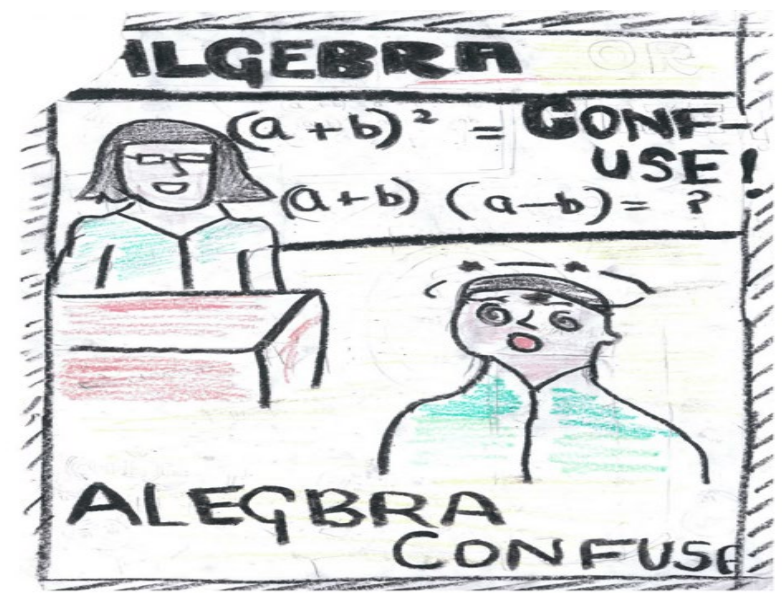

Figure 4. The artwork is titled 'Algebra'. A teacher is at the board writing down algebraic equations. But the student is experiencing confusion, unable to understand the equations. The student is shown with a feeling of head spinning with stars around his head. The artwork is retitled at the end of the page as 'Algebra Confuse'.

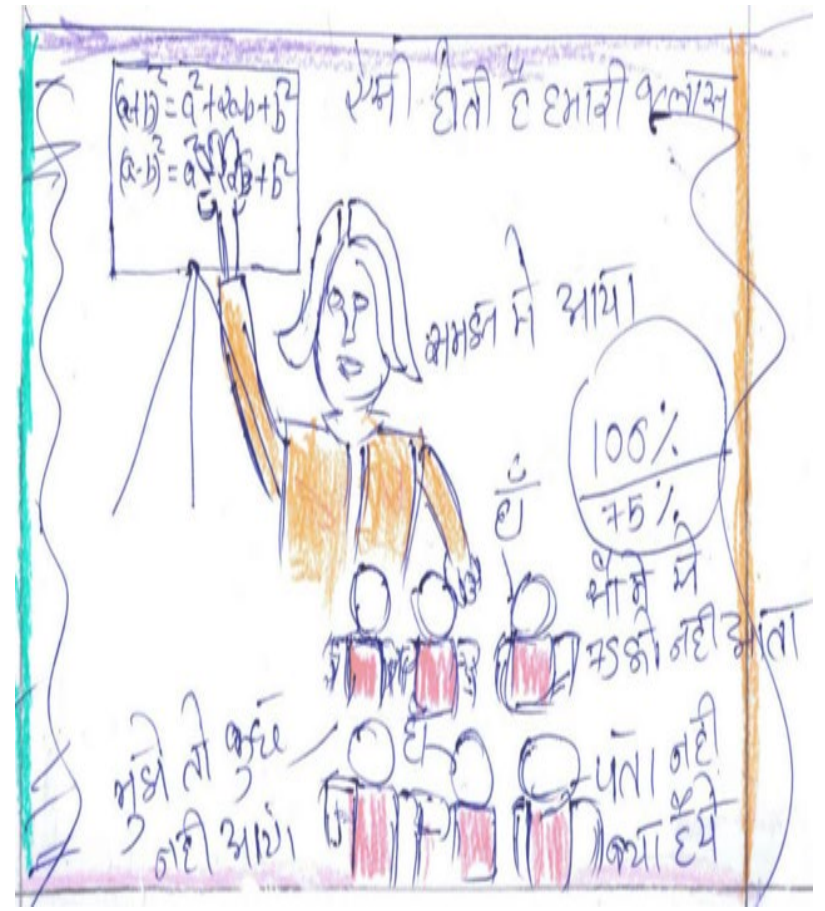

Figure 6. A scene from mathematics classroom shows a teacher at the front of the class teaching algebraic equations. The work is titled 'This is how our class is'. The teacher askes 'did you understand?'. 'Two of the students' reply 'yes', while the others think 'I didn't understand', 'I don't know what this is' ' $75 \%$ of the class cannot understand'. However, the teacher remains oblivious that $75 \%$ of the class does not understand.

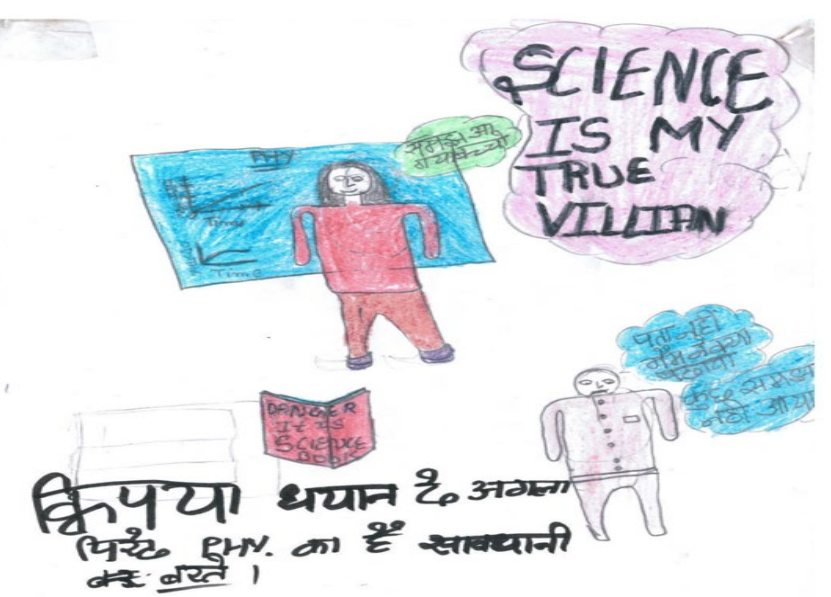

Figure 5. The drawing is titled 'Science is my true villain' depicting student feelings during physics class. The Physics teacher standing before the board is asking, 'Did you understand, students?'. The student is thinking to themself, 'I don't know what the teacher taught, I could not understand anything'. A science book is shown with a Danger warning and a note of caution 'please note that the next period is Physics, be careful'.

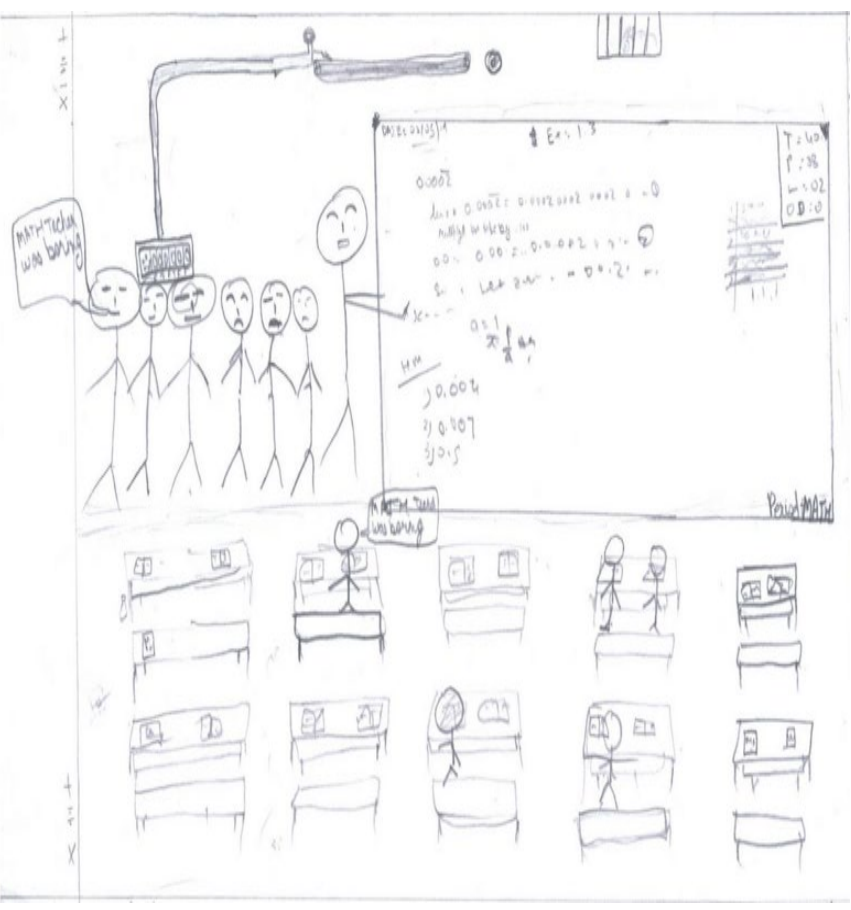

Figure 7. The artwork shows a mathematics classroom with the teacher at the front of the class writing on the board. Several students are leaving the classroom because they feel that the 'math teacher is boring'. Even the students still seated in their places are finding the math teacher boring.

Three out of four students (Figure 4, Figure 5, and Figure 6) depicted teaching approaches that instigated negative emotions towards the subject itself. Forced to assume the role of a passive learner, students felt distanced from the content and teaching process, thus labelling the subject as 'boring', incomprehensible, and a 'danger' to them. This represents a relationship between STEM classroom dynamics during instruction and students' attitude towards the subjects. One student, but, only depicted a 'boring teacher' and not their attitude towards the subject. 


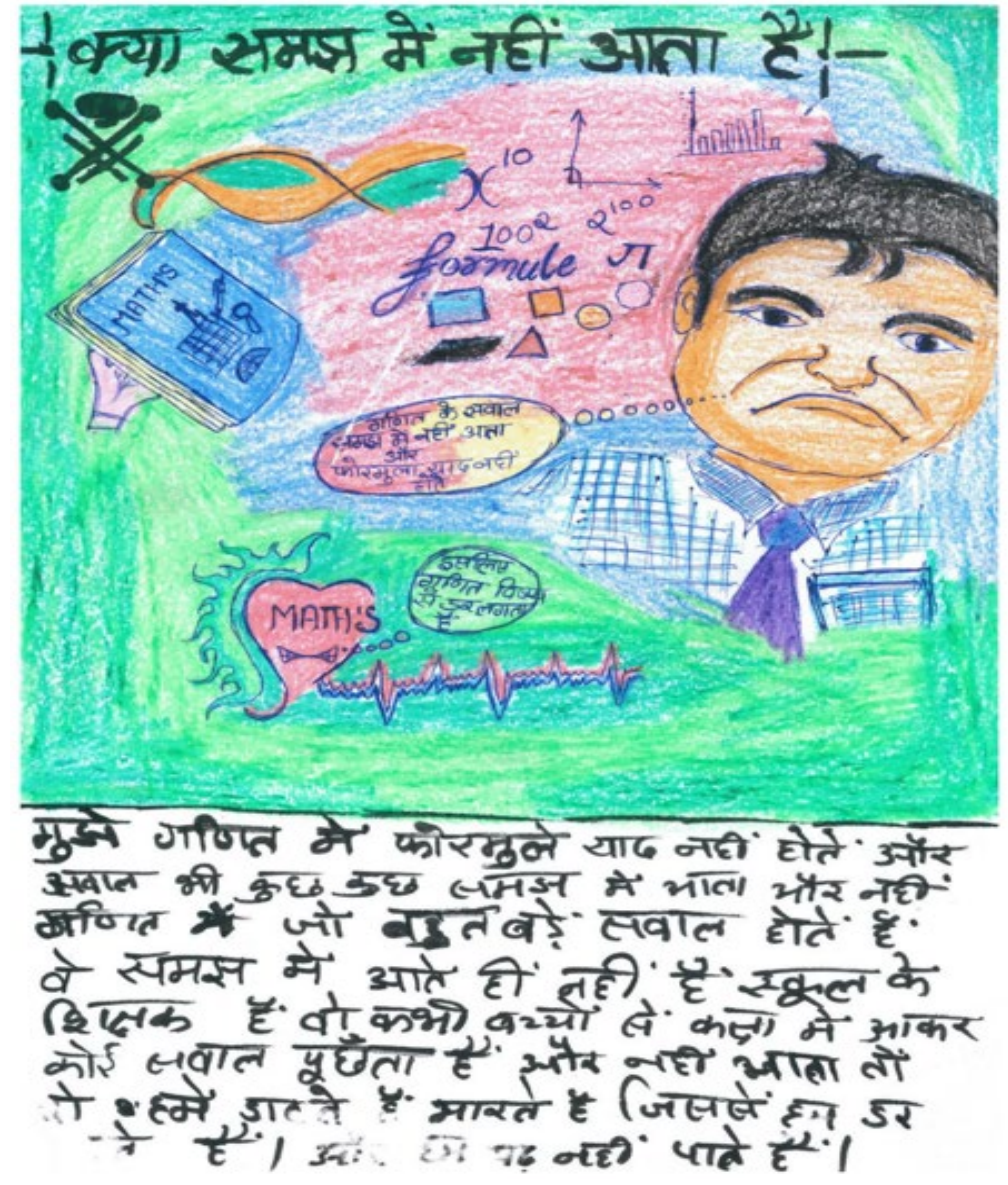

Figure 8. The artwork is titled 'what I don't understand' followed by a danger symbol. Student is thinking to themselves, 'I cannot understand the maths questions and I cannot remember the formulae'. Their heart is shown on fire with an elevated heartbeat, 'this is why I'm scared of maths'. There are several mathematical symbols and textbook in the background. In the test description, student explains, 'I cannot remember mathematics formulae and cannot understand some questions. I absolutely cannot understand the big answer questions in mathematics. The teacher comes to class and askes the students any question. If they cannot answer, they get beaten. This is why we get scared of mathematics and are unable to study.'

\section{Asking a question}

Three student drawings of classroom dynamics indicated unpleasant incidents of questioning by the teacher. One particular student described a scenario in which the maths teacher asked questions in the class and students were then punished if they gave incorrect answers (Figure 8). As a result of this experience, the student reported developing severe emotional and physical reactions towards mathematics while other students in the class also experienced fear and anxiety.

Two other students depicted teachers using a threatening tone while asking questions in the classroom. In both cases, the teachers' behaviour towards the student incites a derogatory reaction of laughing from their peers (Figure 9 and Figure 10). The student from Figure 9 demonstrates a feeling of isolation from their peers due to the dynamic of being put down by the teacher and peers. The student shows an emotional reaction of wanting to burn the mathematics books as a result. However, Figure 10 depicts a comparison of mathematics and science classes. This student drawing indicates that the behaviour of their peers and attitude towards the subject depends on the behaviour of the teacher. Further, classroom experiences lead them either to 'love' or 'hate' the subject.

\section{Teacher Intent}

Based on the student narrative and posters, teachers are sometimes represented in an antagonistic role. However, as researchers who worked closely with these teachers for over a year, we observed that the teachers genuinely had the best interest of the students in mind. Given the residential setting, teachers were also caretakers of the students outside the classroom and shared a close personal bond with many students. Some of the instructional and classroom management practices noted from the student drawings were a norm in India, but do not demonstrate any malicious intent on the part of the teachers. These norms widely accepted as time tested classroom practices were still prevalent because the teachers were unaware of the associated social and emotional experiences of the students. 


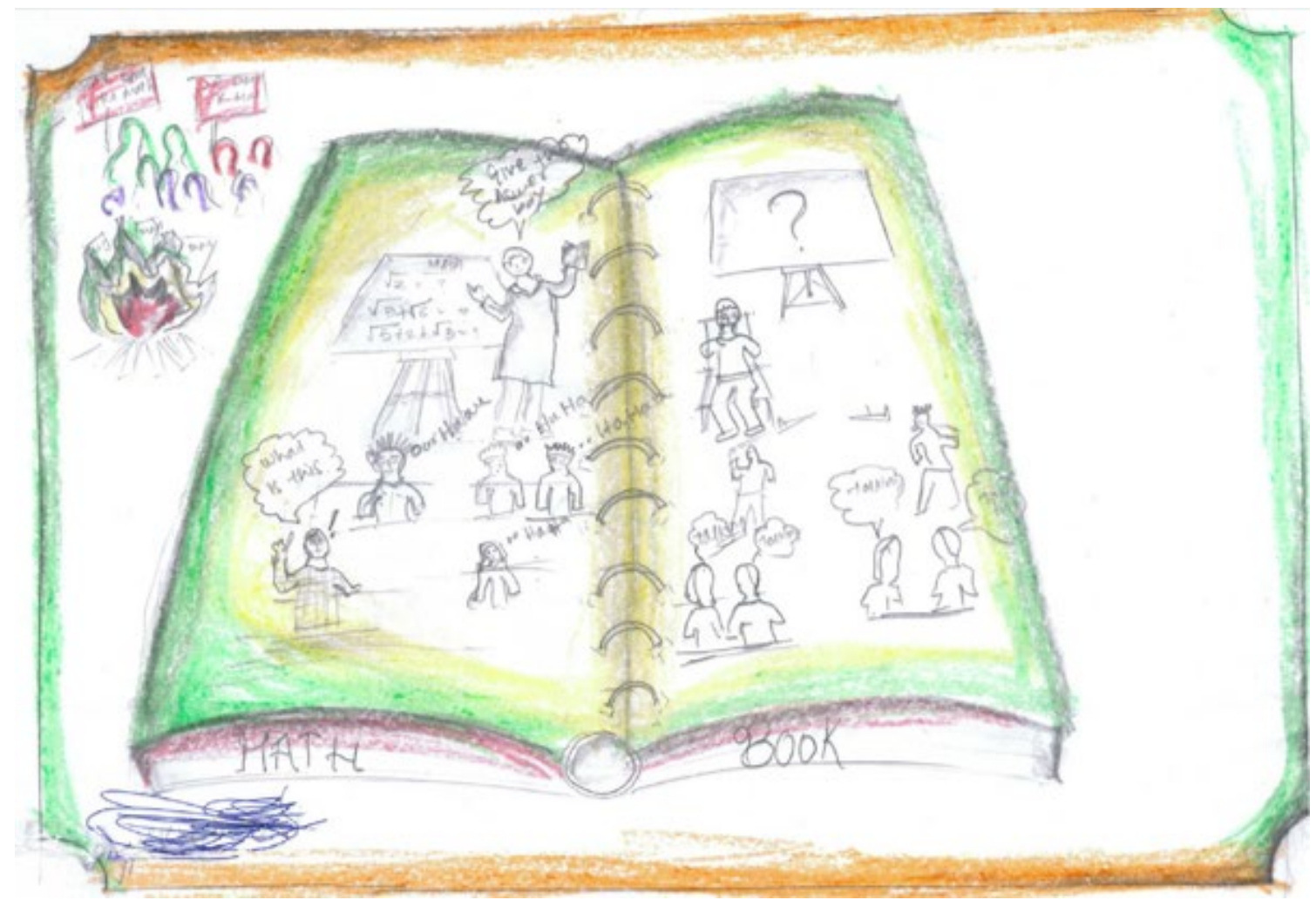

Figure 9. The drawing shows events within a mathematics classroom. In the first scene, the teacher is directing a question towards one student who is unable to answer. She says 'Give me the answer boy', while the other students laugh. In the second scene, the student who was unable to answer is sitting next to a blank board, while the rest of the students are socializing. Outside the classroom, a group of students are expressing their displeasure with mathematics by burning the textbooks.

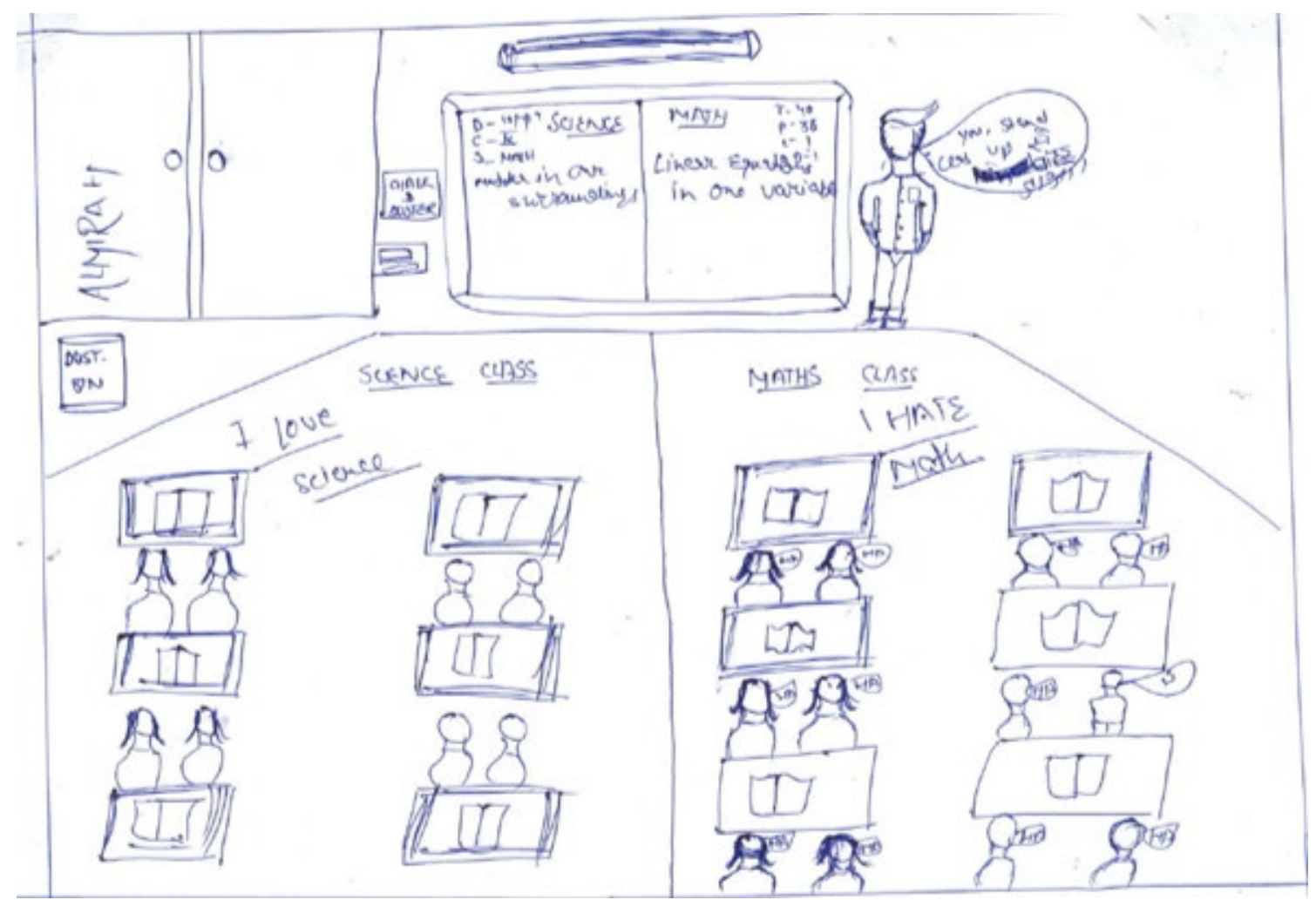

Figure 10. The drawing shows a comparison of maths and science classrooms. While the science classroom appears quiet without a teacher, the mathematics classroom shows the teacher asking a student to 'stand up and get out' while the other students laugh. The picture indicated that the student loves science but hates math. 


\section{DISCUSSION}

In an assessment driven education system, there is a reluctance to move away from established systems which seem to be working well. Specifically, in the Indian context, as many students are still able to perform well academically in rigid educational settings, the students who struggle academically are often looked down upon. However, this study provides insights about the weaknesses in the existing systems that impacts all students. Posters created by students underperforming in mathematics and science demonstrates student experiences in STEM classrooms. The posters provided an opportunity for students to authentically express themselves (Mitchell et al., 2011) and represent the social and emotional consequences of teacher behaviour in STEM classrooms.

Classroom dynamics including student-teacher and student-student interactions in STEM classrooms play an important role in shaping student self-efficacy, attitudes, achievement, and future career choices. Specifically, prior research indicated that students who are identified as 'academically underperforming' by teachers are at risk of biased treatment by teachers and peers (Brey and Pauker, 2019; Howe and Abedin, 2013). As a result, they develop poor self-efficacy and negative attitudes towards the subject (Lee et al., 2015). The results from the current study aligned with existing research as all the students who were identified as academically underperforming in science or mathematics indicated a dislike for one or both of the subjects through their posters. Further, some of the students indicated the existing power dynamic within the classroom through words and illustrations.

Student posters that discussed classroom dynamics clearly indicated a teacher led classroom. Students were able to make connections between teacher behaviours, peer behaviours and their attitudes towards the subject. Specifically, as the classrooms lacked collaborative activities, students were unable to have an active role in their learning. They heavily depended on the teacher feedback and academic performance to evaluate themselves and their peers. As a result, they associated poor academic performance with lower STEM self-efficacy. Some students demonstrated biased treatment due to their academic performance and a causal relationship between rejection in the classroom and dislike towards the subject.

Several images clearly represented the emotional and physical manifestations of STEM related anxiety. Even though some students referred to 'boring' teaching practices, or threatening classroom climate, they did not view the teacher as a threat. Instead, a majority of the students viewed the subjects - mathematics or science or both, as the source of the problem, while representing themselves as victims. Some students were waiting for the day when they no longer needed to engage with mathematics or science. This implied that students had developed strong negative attitudes towards STEM subjects and were unlikely to pursue related careers.

The findings from this study suggest a strong need to reassess teaching practices in rural Indian context. Specifically, there is a need to reconsider teacher led classrooms and outdated teaching techniques involving shaming and harsh punishments. The artifacts generated by students are invaluable tools for facilitating discussions about best practices with pre-service and in-service STEM teachers. In future research and teacher training efforts, we aim to use the student artwork to demonstrate classroom dynamics from the perspective of underperforming students to provoke meaningful pedagogical changes.

\section{ACKNOWLEDGEMENTS}

We wish to thank UNESCO MGIEP where the research project was conducted.

\section{REFERENCES}

Alerby, E. and Bergmark, U. (2012). What can an image tell? Challenges and benefits of using visual art as a research method to voice lived experiences of students and teachers. Journal of Arts and Humanities, 1(1), 95-104.

Alerby, E. and Brown, J. (eds). (2008). Voices from the margins: School experiences of indigenous, refugee and migrant children. Rotterdam, The Netherlands: Sense Publishers. https:/ / doi.org/10.1163/9789087904623

Banerjee, M., Schenke, K., Lam, A. and Eccles, J. S. (2018). The roles of teachers, classroom experiences, and finding balance: A qualitative perspective on the experiences and expectations of females within STEM and non-STEM careers. International Journal of Gender, Science and Technology, 10(2), 287-307.

Barroso, C., Ganley, C. M., McGraw, A. L., Geer, E. A., Hart, S. A. and Daucourt, M. C. (2021). A meta-analysis of the relation between math anxiety and math achievement. Psychological Bulletin, 147(2), 134-168. https:// doi.org/10.1037/bul0000307

Benner, A. D. and Mistry, R. S. (2007). Congruence of mother and teacher educational expectations and lowincome youth's academic competence. Journal of Educational Psychology, 99(1), 140-153. https:/ / doi.org/10.1037/ 0022-0663.99.1.140 
Bracher, E. R. (2003). An investigation of the efficacy of analyzing student drawings as an adjunct to interviews aimed at researching the contexts of student life [Unpublished doctoral dissertation]. Boston College, Boston, MA.

Brey, E. and Pauker, K. (2019). Teachers' nonverbal behaviors influence children's stereotypic beliefs. Journal of Experimental Child Psychology, 188, 104671. https://doi.org/10.1016/j.jecp.2019.104671

Flores, A. (2007). Examining disparities in mathematics education: Achievement gap or opportunity gap? The High School Journal, 91, 29-42. https:// doi.org/10.1353/hsj.2007.0022

Gentrup, S., Lorenz, G., Kristen, C. and Kogan, I. (2020). Self-fulfilling prophecies in the classroom: Teacher expectations, teacher feedback and student achievement. Learning and Instruction, 66, 101296. https://doi.org/ 10.1016/j.learninstruc.2019.101296

Guillemin, M. (2004). Understanding illness: Using drawings as a research method. Qualitative Health Research, 14(2), 272-289. https:// doi.org/10.1177/1049732303260445

Heaverlo, C. A. (2011). STEM development: A student of 6th-12th grade girls' interest and confidence in mathematics and science [Unpublished doctoral dissertation]. Drake University, Des Moines, IA.

Hendrickx, M. M., Mainhard, M. T., Boor-Klip, H. J., Cillessen, A. H. and Brekelmans, M. (2016). Social dynamics in the classroom: Teacher support and conflict and the peer ecology. Teaching and Teacher Education, 53, 30-40. https://doi.org/10.1016/j.tate.2015.10.004

Howe, C. and Abedin, M. (2013). Classroom dialogue: A systematic review across four decades of research. Cambridge Journal of Education, 43(3), 325-356. https:/ / doi.org/10.1080/0305764X.2013.786024

Jocuns, A. (2013). Classroom discourse, in C. A. Chapelle (ed), The encyclopaedia of applied linguistics. Oxford: Blackwell Publishing Ltd. https:// doi.org/10.1002/9781405198431.wbeal0134

Kaya, E. and Yildirim, A. (2014). Science anxiety among failing students. Elementary Education Online, 13, 518-525.

Kayi-Aydar, H. and Miller, E. R. (2018). Positioning in classroom discourse studies: A state-of-the-art review. Classroom Discourse, 9(2), 79-94. https://doi.org/10.1080/19463014.2018.1450275

Koester, M. (2015). Science teachers who draw: The red is always there. Deep University Press.

Lee, S. W., Min, S. and Mamerow, G. P. (2015). Pygmalion in the classroom and the home: Expectation's role in the pipeline to STEMM. Teachers College Record, 117(9), 1-36. https://doi.org/10.1177/016146811511700907

Mannay, D. (2010). Making the familiar strange: Can visual research methods render the familiar setting more perceptible? Qualitative Research, 10(1), 91-111. https://doi.org/10.1177/1468794109348684

Menon, R., Sridharan, A., Sankar, S., Gutjahr, G., Chithra, V. V. and Nedungadi, P. (2021, March). Transforming attitudes to science in rural India through activity based learning. AIP Conference Proceedings, 2336, 040003. https://doi.org/10.1063/5.0046269

Mitchell, C., Theron, L., Smith, A., Stuart, J. and Campbell, Z. (2011). Drawings as research method, in L. Theron, C. Mitchell, A. Smith and J. Stuart (eds), Picturing research (pp.17-36). Sense Publishers. https://doi.org/10.1007/ 978-94-6091-596-3_2

Montague, M. and Rinaldi, C. (2001). Classroom dynamics and children at risk: A followup. Learning Disability Quarterly, 24(2), 75-83. https://doi.org/10.2307/1511063

Nathan, M. J., Tran, N. A., Atwood, A. K., Prevost, A. M. Y. and Phelps, L. A. (2010). Beliefs and expectations about engineering preparation exhibited by high school STEM teachers. Journal of Engineering Education, 99(4), 409-426. https:// doi.org/10.1002/j.2168-9830.2010.tb01071.x

Omatsu, G. (2011). Understanding classroom dynamics: A critical factor in teaching freshmen. California State University. Available at: https://www.csun.edu/sites/default/files/classdynamics.pdf

Ozer, M. (2020). What does PISA tell us about performance of education systems? Bartn University Journal of Faculty of Education, 9(2), 217-228.

Prain, V. and Tytler, R. (2012). Learning through constructing representations in science: A framework of representational construction affordances. International Journal of Science Education, 34(17), 2751-2773. https://doi.org/10.1080/09500693.2011.626462

President's Council of Advisors on Science and Technology (PCAST). (2010). Prepare and inspire: K-12 education in science, technology, engineering, and math (STEM) for America's future. Report to the President. Available at: https://nsf.gov/attachments/117803/public/2a--Prepare_and_Inspire--PCAST.pdf

Puglionesi, A. (2016). Drawing as instrument, drawings as evidence: Capturing mental processes with pencil and paper. Medical History, 60(3), 359-387. https://doi.org/10.1017/mdh.2016.28

Raabe, I. J., Boda, Z. and Stadtfeld, C. (2019). The social pipeline: How friend influence and peer exposure widen the STEM gender gap. Sociology of Education, 92(2), 105-123. https://doi.org/10.1177/0038040718824095

Rose, G. (2001). Visual methodologies. London: SAGE.

Rosenthal, R. and Jacobson, L. (1968). Pygmalion in the classroom: Teacher expectations and pupils' intellectual development. New York, NY: Holt, Rinehart \& Winston.

Schneider, F. W., Coutts, L. M. and Gruman, J. A. (2012). Applied social psychology: Understanding and addressing social and practical problems. Thousand Oaks. CA: SAGE. 
Sjøberg, S. (2015). OECD, PISA, and globalization: The influence of the international assessment regime, in C. H. Tienken and C. A. Mullen (eds), Education policy perils: Tackling the tough issues (pp. 114-145). London: Routledge.

Tsukada, H. and Perreault, A. (2016). Complicating how classroom climate works. Transformative Dialogues: Teaching and Learning Journal, 9(2), 1-17.

UNESCO. (2021). Engineering for sustainable development: Delivering on the sustainable development goals. Available at: https: / / unesdoc.unesco.org/in/documentViewer.xhtml?v=2.1.196\&id=p::usmarcdef_0000375644\&file=/in /rest/annotationSVC/DownloadWatermarkedAttachment/attach_import_bf945451-41f6-4e0b-a5db50a8bb0c399b\%3F_\%3D375644eng.pdf\&locale=en\&multi=true\&ark=/ark: $/ 48223 / \mathrm{pf0000375644/PDF} / 37$ 5644eng.pdf\#p143

Véronneau, M.-H., Vitaro, F., Brendgen, M., Dishion, T. J. and Tremblay, R. E. (2010). Transactional analysis of the reciprocal links between peer experiences and academic achievement from middle childhood to early adolescence. Developmental Psychology, 46(4), 773-790. https://doi.org/10.1037/a0019816

Wang, M. T., Degol, J. L., Amemiya, J., Parr, A. and Guo, J. (2020). Classroom climate and children's academic and psychological wellbeing: A systematic review and meta-analysis. Developmental Review, 57, 100912. https://doi.org/10.1016/j.dr.2020.100912

Wang, S., Rubie-Davies, C. M. and Meissel, K. (2018). A systematic review of the teacher expectation literature over the past 30 years. Educational Research and Evaluation, 24(3-5), 124-179. https:/ / doi.org/10.1080/13803611. 2018.1548798

Watson, P. W. S., Rubie-Davies, C. M., Meissel, K., Flint, A., Peterson, E. R., Garrett, L. and McDonald, L. (2015). Gendered teacher expectations of mathematics achievement in New Zealand: Contributing to a kink at the base of the STEM pipeline? International Journal of Gender, Science and Technology, 8(1), 82-102.

World Economic Forum. (2020). The future of jobs report 2020. World Economic Forum, Geneva, Switzerland.

Zhan, M. and Sherraden, M. (2011). Assets and liabilities, educational expectations, and children's college degree attainment. Children and Youth Services Review, 33(6), 846-854. https://doi.org/10.1016/j.childyouth.2010.12.006 